\title{
The Improvement of Governmental Emergency Procurement on Resolving Public Crisis
}

\author{
Yuan Guang ${ }^{1}$, Wang $\mathbf{Y i}^{2}$ \\ ${ }^{1,2}$ College of Humanities and Law, Shandong University of Science and Technology, \\ Qingdao,P.R.China 266590 \\ (E-mail:YUANSHINE@163.com)
}

\begin{abstract}
Crisis management is a complex systematic project. In order to deal with emergency situation and reduce the cost of crisis management and improve the efficiency of the process, it is necessary to introduce governmental procurement system into public crisis management. By expressing the role that the emergency governmental procurement plays during the public crisis, this paper examines and analyses the particularity of the governmental emergency procurement during public crisis and the difficulties and problems that are often encountered. Based on this, suggestions are made on the innovation of governmental emergency procurement system from six angles: the construction of legal system, judicial involvement, credit records, institution-building, procurement supervision and procurement network. Therefore, we can find methods and ways to maximize the beneficial influences of the system and achieve the effective combination of public crisis management and government procurement system.
\end{abstract}

Keywords: Public Crisis; Governmental Emergency Procurement; Improvement of the System

\section{Introduction}

Public crisis is the kind of crisis, which occurs in public area, and largely hinters the development of economy, endangers social security and stability as well [1]. Governmental procurement is growing much more significant in administration of public crisis recent years. Thus, it is gradually becoming an indispensable method to address the kind of issues. Urgent crisis procurement is an emergency management, which is implemented to meet material requirement and enhance affectivity if necessary. However, the vacancy of related institution is in disharmony of emergency management, and would render vulnerability since there is almost no supportive theory to that. Indeed, there are a small number of practical people who make some suggestions about urgent crisis purchase, but it is obvious that the quantity cannot be systematically organized into a theory. Meanwhile, research results have come out partly from institutes in foreign countries, such as researches of Thomas E.Deabek and so on. But because of system reason, the specific practice and successful experience are very difficult to be transplanted or implemented directly. Thus, in order to deliberate how to develop crisis purchase by means of improving and innovating political system, this dissertation would address and analyze some of major public crisis.

\section{The role of the emergency government procurement in public crisis}

\subsection{Promoting to resolve the public crisis}

Government procurement plays an important role both during and after crisis. It is an effective way to deal with an emergency situation, which is obvious especially in major public crisis. Governmental procurement is indispensable to catastrophe like We chuan Earthquake, as well as global economy crisis, since domestic demand is sensitive to it.

2.2. Operating macro control in public crisis to promote the stability and development of the economic society

Macro control is one of the major functional targets in government purchases. It exists not 
only in normal conditions, but also operates in public crisis, in order to turns around the situation into opportunity.

First of all, emergency government purchase can mitigate the destructive effect and restore social and economic stability.

Secondly, it could break down and optimize the stale and obsolete economic structure, stimulate domestic small and medium enterprise to grow.

Thirdly, it is beneficial to strengthen and enhance the construction of infrastructure, stimulate consumption, expanding job market as well as solidifying economic foundation.

According to the experience of western countries, emergency government purchase always acts an indispensable assistant in overcoming economic crisis. Government would not only increase the investment in infrastructural projects, which can easily incent economical demands, but also expands social welfare to stimulate

2.3. Operating the control- oriented function of the government procurement and standardizing the administrative acts of the government

Regulations of governmental procurement are the basis of this kind of conduct. Without it, government purchases can neither economize spending nor prevent corruption. Thus government purchases are the symbolic icon of clean and frugal office.

The significant effect in public crisis of emergency government procurement is essential to deepen the understanding of government purchases regulation. Through this kind of conduct, fiscal conducts can be regulated, so does the honesty construction. Other than that, it is also an opportunity to guide governmental behaviors. It is not merely a governmental fiscal conduct, but also a demonstrative benchmark, which is essential to improve the atmosphere in governmental office and its social image.

\subsection{Being beneficial of alleviating the external diseconomy}

During the administration of a public crisis, by putting forward technical requests of those purchased goods, it, to some extent, is helpful to improve environmental protection and technical safety. Also, it can polish the external diseconomy [2]. Government purchase would need massive capital injection during a crisis. This can form a strong public opinion of direction of benefit, which is vital to waking up conscientious of enterprise, in order to rise the safety and environmental standard of its products, thus alleviate the negative influence of environmental and other external pollution in economy and society.

\section{The difficulties and problems encountered in the process of emergency governmental procurement}

\subsection{The contradiction between the legitimate operation and the deletion of government procurement rules}

Different from the regulations of US in a major disaster," procurement of relief supplies and equipment, do not need to consider the current regulations ",[3] in China, Military procurement, Emergency procurement, Safe and secret purchase, foreign loan purchase are specific in the supplementary articles of Government Procurement Law. They are four kinds of government procurement types, which could not apply the law. This means that emergency purchasing behavior in the management of public crisis is lawless. The natural disasters and the financial crisis in 2008 to some extent exposed the institutional problems in the process of government emergency procurement.

The state has not yet issued the corresponding implementation rules and formed unified operating rules since the implementation of Government Procurement Law in 2003 [4]. In actual activities local organ procurement basically rely on self -exploration and self-improvement, which not only increases the difficulty of the work but also provides the opportunity for some people who engage in malpractices for selfish ends and fill their own pocket. In the process of public crisis management, this problem is especially prominent. The main reason lies in the lack of corresponding special rules. In general, more urgent the case is, more necessary to prepare. But in fact, the flaws that the legal system is not perfect in the crisis management process are further enlarged. The lack of special rules leads to the situation that no law can be relied on in the process of the emergency governmental procurement. This will make the government procure mental lose its function in crisis management. 


\subsection{The contradiction between procurement specification and time urgency}

In government procurement especially the emergency procurement, some departments do not pay attention to the government procurement specification. They assume that they should do something targeted so they provide the procurement information to suppliers in advance or set some obvious tendency of the technical parameters and the restrictive clause in the process of developing procurement document, which is in favor of some bidders. Some departments will not purchase according to the rules of procedure for time is limited. It would seem that these behaviors are discretionary behaviors as the crisis time. But in fact these behaviors are random behaviors, which is not in accordance with the rules. This is not only difficult to successfully achieve the goal, but also appears new problems sometimes and creates new hazards.

3.3. The contradiction between localized emergency governmental procurement and suppliers' regional monopoly

In public crisis, emergency governmental procurement activities are often in a particular region in order to save time. But for some products containing high technology, manufacturers often use strict sub-regional sales strategy. If suppliers trade across regions, they will be subject to be severely punished. In fact, the manufacturers form a regional monopoly on governmental procurement. As a consequence, an effective competition mechanism of product supplies is difficult to form and the purchase price is difficult to achieve optimization. Certain procurement units or individuals disclose some relative information such as products models, specifications and other information to suppliers, then the suppliers will monopolize products so other suppliers cannot get products and governmental procurement activities fail to delay the process of crisis management.

3.4. The contradiction between the publicity of emergency governmental procurement and the strategic behavior of suppliers

The public interest is the goal of Governmental procurement in the public crisis, but it is usually distracted by self-interested strategic behavior of suppliers. Some unscrupulous suppliers in the tender process compete not by strength rather than improper means. If they are not successful, they will inference with the procurement. If they are successful, they will not provide goods and services in accordance with the tender documents and then affect the efficiency of governmental procurement because they are lack of faith.

3.5. The contradiction between the permanent nature of management agencies and the particularity of their duties

Governmental procurement departments are set in accordance with the conventional situation. So it lack of the ability to deal with to the crisis Once a crisis occurs, procurement departments will have troubles in their responsibilities and rights.

That means that work is difficult to finish and time is limited. What is more, the administrative authority is lack of effective means and measures so that it is difficult to play its due role.

\section{The innovation of emergency procurement system in crisis situations}

As mentioned above, although government procurement in the public crisis is promising, for various reasons, the role of government procurement has not yet been fully realized. Therefore, it is necessary to improve the performance and role of the emergency governmental procurement through institutional innovations; I reckon that it can be tackled from some aspects

\subsection{Strengthening the legal construction of the emergency government procurement and publicity}

We must strengthen the construction of the emergency government procurement. Except from making laws, developing a detailed implementation rules and regulating the behaviors of government procurement is also necessary. In addition, according to the particularity of the crisis, we should develop specialized and targeted special rule to regulate government procurement during crisis. As for this issue, we could draw lesson from the experience of Germany. Before the introduction of economic stimulus bill, German government made provisional measures law, which provide that it can be authorized to shorten the time, required by the relevant tender procedures to deal with the financial crisis. China has also enacted similar interim 
bill and enact emergency procurement management approach about the crisis to compensate for the deficiencies of this.

Since the implementation of the Government Procurement Law, the governmental procurement in China improves greatly. But as for the functions of the governmental procurement goals, such as saving the financial funds, tightening macro-control and the preventing corruption and so on, is not deeply rooted. Especially in City and county governments, officials still lack a deep understanding of governmental procurement and fail to seriously implement the law, which is mainly reflected in the neglect of the governmental procurement specification. Therefore, we must intensify the propaganda of the Government Procurement Law and biding and Tendering law, so they can be deeply rooted as the true basis of governmental procurement.

\subsection{Establishing judicial participation in the emergency procurement decision-making system and promoting the legitimacy of the governmental procurement}

National judicial system, especially the court, should always adhere to the principle of uniformity of law and cannot accommodate the apparent violation of the law of the purchasing behavior at the expense of laws. Those illegal behaviors, which result in the formation of new local protectionism and industrial monopoly and violation of citizens, legal persons and other organizations for violations of the legitimate rights and interests, should be corrected in accordance with the law.

In order to ensure the legitimacy of governmental procurement, all judiciary should actively participate in researching of major policies, which are made by the party committees and the government to deal with the crisis. They also should provide legal advice and suggestions for the Party committees and governments to assist the Chief authorities to improve the system of measures. As a consequence, we could prevent and minimize disputes from the source. In term of problems, which is found in the cases of governmental procurement, we should timely give advice to the relevant administrative authorities.
4.3. Establishing the credit records and blacklist system and creating a fair competition mechanism in emergency governmental procurement

To improve the level of governmental procurement and the development of government procurement, the government needs to take precautions in normal times. They need promote fair competition in the market through price, tax, credit and leverage and other financial means in their daily work to crack down on illegal behaviors and format of a favorable market environment. It is necessary to establish the credit records system in governmental procurement and government give priorities to these corporate with higher credit records to buy their products during the crisis.

In emergency conditions, the combination of the financial and administrative means is an excellent way to cope with the crisis and break the regional monopoly. As for these unscrupulous suppliers, once it is found that that their behavior has caused or may cause a violation of the public interest, they must be severely punished. It is very important to establish the correctional system. Any suppliers who harm the public interest but have not been punished during the crisis should be given more severe punishment as a warning to others. For those dishonest traders, we not only punished them in accordance with the law but also put them in the governmental procurement blacklist and in 10 years or longer shall not purchase any of their products.

\subsection{Improving the emergency government procurement agencies and enriching their administrative functions during crisis}

In term of assets of the procurement agencies, crisis management should be taken into account, which should be reflected, in institutional settings. Setting the crisis procurement leadership group is necessary, which is launched by superiors to define its functions, division of labor and sources of funding. In addition, contingency plans of governmental procurement should be prepared as well as emergency drills. Once a crisis takes place, we should ensure that government procurement departments respond quickly and efficiently under the leadership of emergency leading group. Administrative authority should strengthen the functions and powers of the government procurement agencies during the 
crisis. At the same time we should strengthen supervision and improve the administrative efficiency of governmental procurement.

Government should strengthen the training of practitioners and make training methods written by the relevant departments. What is more, government should systematically train procurement regulators, assessment experts, and agency employees.

4.5. Strengthening the supervision of governmental procurement and establishing audit and examination system of the crisis procurement

Governmental procurement regulation should be strengthened not only in normal times but also in crisis situations.

Firstly, build governmental procurement system with standardized at the core relying on the improvement of the government procurement laws and regulations. Improve the government procurement agency competition mechanism, the formation of the survival of the fittest government procurement market competition. Then, to improve the government procurement agency competition mechanism to form the survival of the fittest government procurement market competition. And improve the overall level of service and extent of regulation of the governmental procurement agencies to promote governmental procurement to develop healthily and orderly.

Secondly, create an open and transparent governmental procurement environment and build a "sun -type" governmental procurement system [5]. Government should further clarify the responsibilities and the division of management bodies and operate organizations to improve the financial sector and institutions for centralized procurement supervision and control mechanisms. And it also should further create an open and fair governmental procurement environment. Government should guarantee the disclosure of information, fair trades and results.

Thirdly, strengthen the supervision of governmental procurement to form "constraint type" governmental procurement regulatory system. Government should establish full scales and multi-level supervision over government procurement system with the combination of internal and external supervision of various departments. They also need to perfect complaint-reporting system, timely investigate illegal activities and promote fair competition. They should strengthen risky aspects' supervision through online publicity the organization argue, seek advice, hearings and other ways to standardize the assessment process and then improve a verification system of governmental procurement projects to strengthen the open construction of the governmental procurement information.

Fourthly, establish the system at all levels of supervision assessment. It is important to introduce national "job of evaluation of the governmental procurement supervision and management approach "as soon as possible, to examine and evaluate all governmental procurement from some angles: supervision and management, information, statistics, governmental procurement, promotion, training and research.

Fifthly, establish the system of crisis procurement audit team or a Commissioner. As for that local, special emergency or governmental procurement with the huge amount, government can be accredited to the audit team or a Commissioner to conduct on-site management. It is beneficial to effectively supervise as well as enhance contract with each level so that the higher level can more quickly and accurately understand the crisis situation, according to the specific needs of coordination of more power, to allocate additional supplies and improve government the efficiency of the procurement.

\subsection{Promoting the development of e-procurement and the emergency procurement network}

E-procurement is an important part of e-government development, which is fast, convenient, efficient and well adapted to the requirements of the procurement of public crisis. At present, China's e-procurement in practice has obtained some development, but overall the e-procurement in China is still in the pilot and has not yet introduced a unified policy and standard. Therefore, we must promote the standardization and technical construction of the electronic procurement system, combined with the more developed e-government system to promote the development of e-procurement.

Firstly, we need to promote the harmonization of standards and systems of e-procurement. They need to unify the scattered standard to meet the uniformity requirements of the market and to promote the 
efficient allocation of resources, breaking down geographical barriers and regional monopolies, as well as securing the potency of the movement of goods to meet the urgency of the requirements of the procurement of the crisis. Therefore, we really need to realize the electronic operation of the government procurement centers at all levels of procurement operations, and promote value-added development and utilization of procurement the main information sharing and information to achieve the efficient procurement of information dissemination and utilization of maximized [6]. Based on this, we could gradually establish a trans-regional governmental procurement business management systems and online parity system and then form product quality and price assessment mechanism.

Secondly, official governmental procurement system should be connected with e-commerce network system with the help of powerful business platform to achieve barrier-free circulation of goods.

Thirdly, establish the preparatory system of routine emergency network. That means according to firms' credit government should build electronic filing system that is an important part of contingency plans to form the green channel of a contingency. Once the crisis occurs, the procurement agencies could purchase required products in the shortest possible time without going through a complex tendering, audit and evaluation procedures which can greatly improve the response speed and response capacity of public crisis.

\section{Conclusions}

Overall, governmental emergency procurement is an important way to tackle public crisis, but its affectivity depends on the level of completion of the system. During public crisis, we need to constantly advance the emergency system of government procurement, make viable, specific rules according to the feature of a crisis and put the rules into strict enforcement so that the value of governmental emergency procurement can be well reflected.

\section{References}

[1] Xiao Pengjun.Introduction of Public Crisis[M].Beijing:Press of Renmin University of China, 2006(In Chinese)
[2] Guo Xiaocong. Government Economics[M].Beijing: Press of Renmin University of China, 2008(In Chinese)

[3] David A. McEntire. Why vulnerability matters: Exploring the merit of an inclusive disaster reduction concept[J].Disaster Prevention and Management, 2005(2):206 $-222$

[4]Wu Xiaoming.Supporting the Development of Small and Medium-sized Enterprises and Develop -ing Governmental Procurement [N]. China Finance newspaper,2009-6-17(3)(In Chinese)

[5]Yuhua District Government procurement centers. Making the Government Purchasing Power in the Sun $[\mathrm{J}]$, China Government Procurement,2008, (8):12(In Chinese)

[6]Wang Xuedong, Ma Jing. On China 's Consideration of Effectiveness Evaluation of Governmental E-procurement [J].Value evaluation, 2006, (12):77(In Chinese) 